\title{
Adults who survived repair of congenital oesophageal atresia and tracheo-oesophageal fistula
}

\author{
P Chetcuti, N A Myers, P D Phelan, S W Beasley
}

\begin{abstract}
One hundred and twenty five adults who were born before 1969 with oesophageal atresia or tracheooesophageal fistula or both and were managed at the Royal Children's Hospital, Melbourne, were reviewed. Most enjoyed a normal life. Though over half had difficulties in swallowing and symptoms of gastro-oesophageal reflux, the symptoms occurred only occasionally and were regarded as inconsequential by most. One third of the patients had wheeze and a quarter had at least one episode of bronchitis a year, but these interfered little with daily activities. Overall, these results are encouraging for young patients with oesophageal atresia and their families.
\end{abstract}

\section{Introduction}

The successful correction of major congenital malformations is one of the notable achievements of paediatric surgery in the past 40 years. Considerable morbidity, however, may result from the surgical procedures. Now that large numbers of patients with corrected major malformations have reached adulthood, knowledge of their state of health and continuing problems may be important to paediatricians, paediatric surgeons, obstetricians, and genera practitioners who counsel the parents of newborn infants with those anomalies. Parents often ask about the long term outcome of their child's condition.

Oesophageal atresia is uncommon, occurring in about one in 4500 live births.' Survival was first documented in the late 1930s, " but with advances in perioperative care the survival rate has increased from roughly $60 \%$ in the 1950 s to over $80 \%$ at present. ${ }^{+>}$In survivors the morbidity from gastrointestinal and respiratory complications during infancy and childhood is well documented. ${ }^{x / 11}$ Recurrent bronchitis, pneumonia, anastomotic strictures, and dysphagia all can impair the quality of life and cause considerable problems to the patients, their families, and their medical attendants.

There are no published data on whether these problems continue into adult life. We therefore reviewed those adults who had survived repair of oesophageal atresia in a large paediatric centre.

General Surgery and

Thoracic Medicine, Royal

Children's Hospital, Melbourne

PChetcuti, MRCP, research

fellow, department of

paediatrics

N A Myers, FRACS, senior surgeon, department of general surgery

P D Phelan, FRACP, professor of paediatrics and chief

thoracic physician, department of thoracic medicine

S W Beasley, FRACS, lecturer. department of paediatrics and surgeon, department of general surgery

Correspondence to: Professor P D Phelan,

Department of Paediatrics, Royal Children's Hospital, Parkville 3052, Victoria, Australia.

\section{Method}

Two hundred and forty eight patients with oesophageal atresia or tracheo-oesophageal fistula, or both, were managed at this hospital between the time of the first successful repair in 1948 to the end of 1968. A total of 145 patients survived to at least 18 years of age; of these, 107 attended for review and a further 18 patients were interviewed by telephone ( $86 \%$ of survivors). All case notes were reviewed for details of surgical repair, postoperative complications, and subsequent hospital admissions. Details of past medical history and current state of health, particularly gastrointestinal and respiratory symptoms, were obtained from the patients and where possible the parents. Current symptoms were defined as those present in the 12 months before the review. Each patient was examined and the height and weight recorded. Renal ultrasonography was carried out. Other radiological examinations were performed if there was a clinical indication.
Total lung capacity, vital capacity, residual volume, and forced expiratory volume in 1 second were measured in a pressure compensated integrated flow plethysmograph (Jaegar Bodyscreen 2). The best of three efforts was recorded. All values were expressed as "per cent predicted" for height, age, and sex..$^{1213}$

The $\chi^{2}$ test and Student's unpaired $t$ test were used for comparative statistical analysis. Significance was taken as $\mathrm{p}<0.05$.

\section{Results}

The oldest patient reviewed was the first survivor, aged 39 . The mean age of the 68 men $(54 \%)$ and 57 women $(46 \%)$ was 25.0 years. The current problems were distributed evenly between the sexes. Table I gives details of the operations and complications for 145 survivors. The associated congenital abnormalities were as follows: cardiac 10 men and seven women; anorectal 9,6; renal 27, 19; vertebral 19, 13; digital 6,4 ; and other 19,13 . One patient had chronic respiratory problems and short stature related to surgical complications, another had congenital rubella with associated ocular and auditory abnormalites, four patients were mentally retarded but the cause was unknown, and one patient became paraplegic after surgery to correct a congenital scoliosis. Radial anomalies were not detected in any patient.

TABLE I-Surgical procedures and complications in 145 survivors of oesophageal atresia or tracheo-oesophageal atresia, or both, born before 1969. (Figures are numbers of patients with percentages in parentheses)

\begin{tabular}{|c|c|c|c|}
\hline & $\begin{array}{l}\text { Oesophageal } \\
\text { atresia + distal } \\
\text { fistula }\end{array}$ & $\begin{array}{l}\text { Oesophageal } \\
\text { atresia without } \\
\text { fistula }\end{array}$ & $\begin{array}{l}\text { Tracheo- } \\
\text { oesophageal } \\
\text { fistula }\end{array}$ \\
\hline Surgery: & 134 & 5 & 6 \\
\hline Anastomosis & 133 & 3 & \\
\hline $\begin{array}{l}\text { Primary oesophageal } \\
\text { replacement } \\
\text { Surgical complications: }\end{array}$ & 1 & 2 & \\
\hline $\begin{array}{l}\text { Anastomotic leak } \\
\text { Anastomotic stricture } \\
\text { Recurrent fistula }\end{array}$ & $\begin{array}{l}26(18 \cdot 7) \\
76(54 \cdot 7) \\
10(7 \cdot 1)\end{array}$ & & \\
\hline
\end{tabular}

\section{HEIGHT, WEIGHT, AND LUNG FUNCTION}

The distribution of height and weight centiles in the patients is shown in the figure. Only one patient was below the third centile for weight and three patients were below the third centile for height.

\section{GASTROINTESTINAL PROBLEMS}

Table II lists the current symptoms. Difficulties with swallowing occurred often, and many patients drank fluids with their meals. Only two, however, avoided certain foods because of this, particularly meats, poultry, and bread, and one avoided restaurants. Dysphagia was more common in patients who had been in hospital in childhood for stricture (76 out of 125) $(\mathrm{p}<0.05)$. Though symptoms of reflux were common, only one patient had secondary complications. He had a hiatus hernia and a mild oesophageal stricture distinct from the anastomotic site. There was no relation between reflux and dysphagia in the past 12 months.

\section{RESPIRATORY PROBLEMS}

Table II also lists the current respiratory symptoms and illnesses. Thirty patients $(24 \%)$ had attended a 

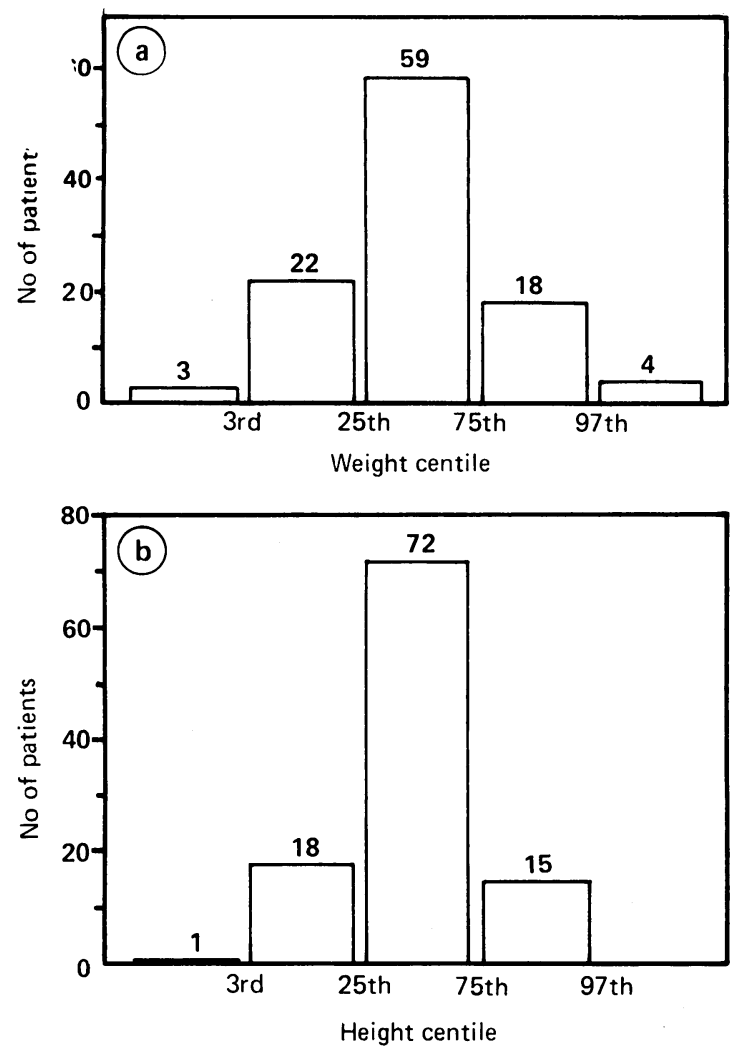

Numbers of patients and distribution between $3 r d$ and 97 th centiles for weight (a) and height (b)

general practitioner for respiratory problems in the preceding 12 months. Asthma was a past or present diagnosis in 17. Seven patients had radiologically confirmed pneumonia after age 18 . The characteristic harsh barking cough of tracheomalacia was present in 50 patients $(40 \%)$. Two patients, one with severe scoliosis and one with bronchiectasis, had a moderate reduction in exercise tolerance. Seven patients had surgically treated scoliosis and 19 mild thoracic scoliosis. None had symptoms.

Forty three per cent of the patients $(33$ men and 21 women) were smokers. The rate in the community for an equivalent age group is $40 \% .^{14}$ There were no differences in frequency of respiratory problems between

TABLE II-Current gastrointestinal and respiratory symptoms

\begin{tabular}{|c|c|c|}
\hline & No & $\%$ \\
\hline \multicolumn{3}{|l|}{ (iustrointestinal simploms } \\
\hline \multicolumn{3}{|l|}{ Dysphagia: } \\
\hline Occasional & 67 & 53 \\
\hline Daily & 16 & 13 \\
\hline \multicolumn{3}{|l|}{ "Heartburn" } \\
\hline Occasional & 57 & 46 \\
\hline$>$ One episode a week & 14 & 11 \\
\hline Respiratory symptoms and illnesses: & & \\
\hline Appreciable daily cough & 11 & 9 \\
\hline $\begin{array}{l}\text { Daily productive cough of greater than one month's } \\
\text { duration }\end{array}$ & 8 & 6 \\
\hline \multicolumn{3}{|l|}{ Whee\%: } \\
\hline Occasional & 32 & 26 \\
\hline$>$ One episode a week & 17 & 14 \\
\hline \multicolumn{3}{|l|}{ Bronchitis: } \\
\hline Once a year & 18 & 14 \\
\hline Two or more episodes a year & 12 & 10 \\
\hline
\end{tabular}

TABL.E III-Lung function (expressed as means (2SD) of the per cent predicted values) in 73 adults who survived repair of oesophageal atresia or tracheo-oesophageal fistula, or both

\begin{tabular}{lcccc}
\hline & Non-smokers & $\begin{array}{c}\text { No whee\% in } \\
\text { past } 12 \text { months } \\
(\mathbf{n}=30)\end{array}$ & $\begin{array}{c}\text { Whee\% in } \\
\text { past } 12 \text { months } \\
(\mathbf{n}=43)\end{array}$ \\
\hline All patients & $99(12)$ & $100(12)$ & $101(11)$ & $98(13)$ \\
$\begin{array}{l}\text { Total lung capacity }(\%) \\
\text { Residuacity (\%) }\end{array}$ & $91(13)$ & $92(12)$ & $9+(12)$ & $87\left(14^{\star}\right)$ \\
Forced expiratory volume in 1 second & $135(77)$ & $142(103)$ & $138(98)$ & $130(28)$ \\
$\left.85(1)^{\star}\right)$ & $85(12)$ & $88(12)$ & $80\left(14^{\star}\right)$ \\
\hline
\end{tabular}

$\star<\mathrm{p}<0.05$ smokers and non-smokers. Wheezing, bronchitis, and persistent cough were more common in patients who had these problems in childhood $(\mathrm{p}<0.001)$. A daily cough was associated with current symptoms of reflux $(\mathrm{p}<0.05)$ and dysphagia $(\mathrm{p}<0.05)$.

Table III gives the data on lung function tests. The following were excluded: 27 patients with scoliosis, two pregnant women, the patient with rubella embryopathy, and four who were mentally retarded. Though values for vital capacity and forced expiratory volume in 1 second were reduced, the results were within the normal range of $80-120$. Residual volume was increased. Lung function in smokers and non-smokers was similar. Patients who wheezed in the 12 months before the review had significant reductions in vital capacity and forced expiratory volume in 1 second $(p<0.05)$. Lung function in patients with other respiratory or gastrointestinal symptoms was not significantly different from that in asymptomatic patients.

\section{LIFESTYLE}

Almost all patients enjoyed a normal lifestyle. Only four patients were unemployed $(3 \cdot 6 \%$ of those employable against a community unemployment rate of $8 \%$ ). Their occupations were comparable to their peers'. Sixty patients were married and marriage breakdown was not outside the community norms. Three of the 55 children of the patients had other prominent congenital anomalies-duodenal atresia, pyloric stenosis, and scimitar syndrome (partial anomalous pulmonary venous drainage with lung hypoplasia). Six patients ( $2 \cdot 7 \%$ of those employable) had lost more than 10 days' work in the preceding year for respiratory disorders, and none had lost more than 10 days for gastrointestinal disorders. Two patients were admitted to hospital for respiratory problems after age 18 and four (3\%) for gastrointestinal problems, whereas $81(65 \%)$ had been in hospital for gastrointestinal problems in the first 10 years of life and $47(38 \%)$ for respiratory problems. One third of the patients exercised a minimum of twice a week and a further third participated in sport occasionally. Only two patients thought that they were appreciably incapacitated by their continuing respiratory and gastrointestinal symptoms.

\section{Discussion}

The results of this first long term follow up of a substantial number of adult patients with repaired oesophageal atresia or tracheo-oesophageal fistula, or both, is reassuring. While over half had daily gastrointestinal symptoms that could be related to the anatomical consequences of the repaired atresia and about a quarter had appreciable respiratory problems, almost all regarded these as having little impact on their daily life. The data should allow those who counsel the parents of an infant with such malformations to give a positive picture about long term health even though there may be considerable problems in the early years of life. Perhaps also those who question allocating scarce health resources to the management of rare complex congenital anomalies will be convinced that it is extremely worth while.

Nevertheless, morbidity in early to middle childhood in patients who have had an oesophageal atresia repaired is common, with frequent readmissions for respiratory illness, surgical complications, and other congenital abnormalities. Further surgery at the anastomotic site $\mathrm{e}^{-11 !}$ ! and gastro-oesophageal junction may be necessary, and the social, psychological, and emotional implications for the child and family are considerable. ${ }^{1}$

Dysphagia was present in over half the adults, but most enjoyed a normal diet and seldom required medical attention. The main cause of the swallowing 
difficulty was probably disordered oesophageal peristalsis, which all patients with oesophageal atresia may have. ${ }^{101617}$ Factors that contribute to the disordered motility are mobilisation of the oesophagus with damage to its neurovascular supply during thoracotomy ${ }^{18}$ and abnormal development of the myenteric plexus of the upper gastrointestinal tract. ${ }^{19}$ Anastomotic stricture is an important cause of dysphagia in the years just after surgery but not in subsequent years.

Symptoms of gastro-oesophageal reflux are common in adults in the general population, with a prevalence of occasional symptoms in $36 \%$ and symptoms occurring more than once a week in $7 \%{ }^{20}$; we found only slightly more in our study. In a patient with a repaired oesophageal atresia the following may contribute to gastro-oesophageal reflux: mobilisation of the lower oesophageal segment, which may produce traction on the lower oesophagus with distortion of the gastrooesophageal junction ${ }^{21}$; interference of the neurovascular supply of the lower oesophagus ${ }^{19}$; abnormal development of the myenteric plexus ${ }^{20}$ or hiatus; and gastrostomy ${ }^{7}$ if carried out.

Respiratory problems were less prevalent than they had been in early childhood. ${ }^{8}$ There are no studies of the prevalence of respiratory symptoms and illnesses in a comparable group of healthy adults, and the difficulties in defining disease, such as asthma and bronchitis, make accurate comparisons difficult. ${ }^{22}{ }^{23}$ One study from general practice, however, reports a prevalence of bronchitis of about three per 100 population for age groups $15-44,{ }^{23}$ which is much lower than what we found.

Among the many factors that contribute to respiratory problems after oesophageal atresia repair is recurrent inhalation secondary to either abnormal oesophageal motility or gastro-oesophageal reflux, which produces increased bronchial hyperreactivity and infections of the lower respiratory tract in childhood. ${ }^{84}$ The results of a recent study on small numbers of survivors of oesophageal atresia showed no association between abnormalities of respiratory function and abnormal lower oesophageal sphincter pressure or the presence of reflux, suggesting that abnormal oesophageal motility is a more important factor. ${ }^{16}$

Tracheomalacia ${ }^{25}$ and squamous metaplasia of the tracheal mucosa ${ }^{26}$ with loss of cilial activity may also contribute to the respiratory problems by interfering with the clearance of mucus. Tracheomalacia is the cause of the typical tracheo-oesophageal fistula "TOF" cough and may facilitate the development of expiratory wheezing with intercurrent lower respiratory infections.

The prevalence of smoking in the group is disturbing, though it was not possible to show that smoking contributed to current symptoms. This group had respiratory symptoms, however, and may have an increased risk of long term tobacco induced lung disease.

Most adults who were born with oesophageal atresia and survived surgery are enjoying a normal life. Those who have minor gastrointestinal and respiratory symptoms generally perceive them as having little consequence. These patients lose little time from work and rarely need to go into hospital. They are a credit to the paediatric surgical achievements of the past 40 years.

We are grateful to $\mathrm{Mr}$ Max Kent, $\mathrm{Mr} \mathrm{A}$ W Auldist, and $\mathrm{Mr}$ Keith Stokes for permission to study their patients and for advice and encouragement and to Miss Jocelyn Brady for finding the patients and arranging the reviews. The study was supported by the Oesophageal Atresia Auxiliary of the Royal Children's Hospital and the Royal Children's Hospital Research Foundation.
1 Myers NA. Oesophageal atresia: the epitome of modern surgery. Ann $R$ Coll Surg Engl 1974;54:277-87.

2 Ladd WE. The surgical treatment of esophageal atresia and tracheoesophageal fistulas. $N$ Engl f Med 1944;230:625-37.

3 Leven NL. Surgical management of congenital atresia of the esophagus with tracheoesophageal fistula. Report of two cases. $\mathcal{F}$ Thorac Surg 1936;6:30.

4 Mvers NA. Oesophageal atresia and or tracheooesophageal fistula. A study of mortality. In: Rickham PP, Hecker WC, Prevot S, eds. Causes of postoperative death in children. Baltimore: Urban and Schwarzenberg, 1979:141-65

5 Holder TM, Cloud DT, Lewis JE, Pitting GP. Esophageal atresia and tracheoesophageal fistula. A survey of its members by the surgical section of the American Academy of Pediatrics. Pediatrics 1964;34:542-9.

6 Waterston DJ, Carter REB, Aberdeen E. Oesophageal atresia: tracheooesophageal fistula: a study of survival in 218 infants. Lancet 1962;i:819-22. Spitz L, Kielv E, Brereton RJ. Esophageal atresia: five vear experience with 148 cases. F Pediatr Surg 1987:22:103-8.

8 Dudley NE, Phelan PD. Respiratory complications in long term survivors of oesophageal atresia. Arch Dis Child 1976;51:279-82.

9 Crispin AR, Friedland GW, Waterston DJW. Aspiration pneumonia and dysphagia after technically successful repair of oesophageal atresia. Thorax 1966;81:104-10.

10 Huks LM, Mansfield PB. Esophageal atresia and tracheoesophageal fistula Review of thirteen years experience. I Thorac Cardiovasc Surg 1981;81 $358-63$

11 Myers NA. Oesophageal atresia with distal tracheo-oesophageal fistulalong term follow-up. In: Rickman PP, Hecker WC, Prevot J, eds. Progress in Pediatric Surgery. Vol 10. Baltimore: Urban and Schwarzenberg, 1977:5-17.

12 Knudson RJ, Slatin RC, Lebowitz MD. The maximal expiratory flow volume curve. Normal standards, variability and effects of age. Am Rev Respir Dis 1976;113:587-600

13 Knudson RJ, Lebowitz MD, Holberg CJ, Burrows B. Changes in the normal maximal expiratory flow-volume curve with growth and aging. Am Rev Respir Dis 1983;127:724-34

14 Anti-Cancer Council of Victoria. Australian smoking rates by age and sex. Melbourne: Anti-Cancer Council of Victoria, 1983

15 Koop CE, Schnaufer L, Thompson G, Haecker T, Dalrymple D. The social, psychological and economic problems of the patient's family after successful repair of esophageal atresia. $Z$ Kinderchir 1975:17:125-31.

16 Le Souef PN, Myers N, Landau LI. Etiological factors in long-term respiratory function abnormalities following esophageal atresia repair. 7 Pediatr Surg 1987:22:918-22.

17 Laks H, Wilkinson RH, Schuster SR. Long term results following correction of esophageal atresia with tracheoesophageal fistula: a clinical and cinefluorographic study. F Pediatr Surg 1972;7:591-7.

18 Lister J. The blood supply of the oesophagus in relation to oesophageal atresia Arch Dis Child 1964;39:131-7.

19 Nakazato Y, Landing BH, Wells TR. Abnormal Averbach plexus in the esophagus and stomach of patients with esophageal atresia and tracheoesophageal fistula. F Pediatr Surg 1986;21:831-7.

20 Nebel OT, Fomes MF, Castell DO. Symptomatic gastroesophageal reflux incidence and precipitating factors. American Journal of Digestive Diseases 1976:21:953-6.

21 Holder TM. Aschcroft KW. Developments in the care of patients with esophageal atresia and tracheoesophageal fistula. Surg Clin North Am 1981;61:1051-61.

22 Ayres JG. Trends in asthma and havfever in general practice in the United Kingdom 1976-83. Thorax 1986;41:111-6.

23 Ayres JG. Seasonal patterns of acute bronchitis in general practice in the United Kingdom 1976-83. Thorax 1986;41:106-10.

24 Milligan DWA, Levison H. Lung function in children following repair of tracheoesophageal fistula. 7 Pediatr 1979;95:24-7.

25 Wailoo MP, Emery JL. The trachea in children with tracheo-oesophagea fistula. Histopathologv 1979;3:329-38.

26 Emery J, Haddaden A. Squamous epithelium in respiratory tract of children with tracheo-oesophageal fistula. Arch Dis Child 1971;46:236-42.

(Accepted 2I April 1988

\section{ANY QUESTIONS}

Should there be a time limit on treatment with tamoxifen in an elderly woman who developed a secondary tumour in a supraclavicular gland five years after mastectomy for breast cancer?

There have been no randomised studies in patients with advanced breast cancer to determine how long tamoxifen should be continued once a response has been achieved. Thus it is common practice to continue treatment until there are obvious signs of progressive disease, particularly as tamoxifen is generally so well tolerated. Progressive disease during one form of endocrine treatment, however, does not preclude further trials of hormonal treatment since it has been established that patients may respond to second line endocrine manipulations. '-JANINE L MANSI, senior registrar in oncology, London.

1 Powles TJ, Ashley S, Ford HT, et al. Treatment of disseminated breast cancer with tamoxifen, aminoglutethimide, hydrocortisone, and danazol, used in combination or sequentially. Lancet 1984;i: 1369-73. 